\title{
PEMODELAN KURVA IMBAL HASIL DAN KOMPUTASINYA DENGAN PAKET SOFTWARE RCMDRPLUGIN.ECONOMETRICS
}

\author{
Dedi Rosadi ${ }^{1}$ \\ ${ }^{1}$ Program Studi Statistika Jurusan Matematika FMIPA UGM \\ Email: dedirosadi@ugm.ac.id
}

\begin{abstract}
In this paper discussed the yield curve modeling methodology using the Nelson-Siegel model Svenson (Svensson, 1994) with special application to model the Indonesian Government Securities Yield Curve. The focus of this study is the computation of the yield curve model using the R, especially using a tool called the R-GUI RcmdrPlugin.Econometrics (Rosadi, 2011). For the empirical illustration, also given examples of applications using real data from the Indonesian capital market.
\end{abstract}

Keywords: Kurva yield, R-GUI, Nelson-Siegel-Svenson

\section{Pendahuluan}

Didalam aplikasi praktis, nilai relatif dari obligasi tidak dapat dilihat dengan membandingkan harga obligasi secara langsung, karena nilai obligasi dipengaruhi faktor waktu jatuh tempo yang berbeda, nilai tingkat kupon yang berbeda-beda, dan lain-lain, sehingga nilai obligasi yang rendah tidak dapat diartikan merupakan harga yang terbaik untuk suatu obligasi. Oleh karena itu untuk menghitung nilai relatif, investor akan membandingkan nilai yield obligasi. Nilai yield biasanya dihitung dalam basis tahunan.

Suatu analisis yang menjelaskan hubungan antara hasil hingga jatuh tempo (yield to maturity) dari obligasi berkupon nol yang bebas resiko (default-free) dengan waktu jatuh tempo obligasi disebut struktur jangka waktu suku bunga (term structure of interest rate). Struktur jangka waktu ini digambarkan dengan grafik yang memuat yield untuk masing masing waktu jatuh tempo. Kurva ini sering disebut dengan kurva imbal hasil (yield curve). Suatu kurva yield di konstruksikan dari sejumlah obligasi yang sejenis, yakni sebagai contoh, kurva imbal hasil tidak akan digunakan secara bersamaan untuk obligasi pemerintah dan obligasi perusahaan, karena keduanya mempunyai struktur risiko yang berbeda. Salah satu model standar untuk pemodelan kurva imbal hasil adalah kelas model Nelson and Siegel (1987). Model dalam kelas ini sudah sangat populer dikalangan praktisi, peneliti dan akademisi yang bekerja pada bidang keuangan dan ekonomi (lihat misal Stander, 2005; dan Rosadi, Gunardi, Abdurakhman, Utami, and Wulansari, 2008; untuk studi mengenai berbagai model untuk kurva imbal hasil).

Tulisan ini secara khusus mempelajari model Nelson-Siegel-Svensson (NSS), dengan fokus utama adalah pada kajian komputasi dari model menggunakan software R.

Pembahasan paper ini dapat dijelaskan sebagai berikut. Pada bagian berikut, akan dijelaskan secara singkat mengenai kurva imbal hasil dan model NSS. Pada bagian selanjutnya, diberikan overview komputasi dari model menggunakan $\mathrm{R}$, dan selanjutnya pada bagian akhir, diberikan contoh kajian empirik menggunakan data real dari bidang keuangan di Indonesia. 


\section{Kurva Imbal Hasil dan Estimasinya}

Berikut akan diberikan beberapa konsep dasar dari pemodelan kurva imbal hasil. Jika $P(t, T)$ adalah harga dari obligasi tanpa kupon (zero coupon bond) pada waktu ke $t$ dengan waktu jatuh tempo adalah $T$, seringkali disebut juga sebagai discount function dan $R(t, T)$ menunjukkan nilai spot rate (yakni continuously compounded zero-coupon nominal yield to maturity atau nilai YTM), maka kurva diskonto dapat diperoleh dari kurva imbal dengan formula $P(t, T)=e^{-(T-t) R(t, T)}$. Dengan demikian diperoleh

$$
R(t, T)=-\ln P(t, T) /(T-t) .
$$

Misalkan $f(t, T, T+\Delta t)$ adalah forward rate untuk suatu kontrak yang ditentukan pada $t$ dengan waktu pelaporan $T$ dan waktu jatuh tempo $\mathrm{T}+\Delta \mathrm{t}$. Fungsi instantaneous forward rate $f(t, T, T+\Delta t)_{\text {inst }}$ didefinisikan sebagai nilai forward rate dengan $\Delta \mathrm{t} \rightarrow 0$, yakni instantaneous forward rate dapat ditulis sebagai $\mathrm{f}(\mathrm{t}, \mathrm{T})$. Hubungan diantara harga zero coupon bond dengan instantaneous forward rate diberikan dengan persamaan $P(t, T)=\exp \left(-\int_{t}^{T} f(t, u) d u\right)$ atau $f(t, T)=-\frac{d}{d t} \ln P(t, T)$ sehingga diperoleh hubungan diantara nilai YTM dan forward rate sebagai $R(t, T)=\int_{t}^{T} f(t, u) d u /(T-t)$. Dengan demikian nilai zero-coupon yield dapat dinyatakan sebagai bentuk rata-rata terbobot (dengan bobot yang sama untuk setiap periode waktu) dari forward rates. Dengan cara yang ekuivalen, maka harga dari obligasi berkupon dapat dinyatakan sebagai jumlahan dari nilai sekarang dari semua cash flow dimasa yang datang (berupa pembayaran kupon dan pembayaran nilai prinsipal), jika diketahui kurva imbal hasil atau forward-rate curve.

Di dalam literatur dikenal berbagai model untuk pemodelan kurva imbal hasil, yang secara umum dapat dikelompokkan kedalam tiga kelas model, yakni model spline/non parametrik, model fungsional/parametrik dan model stokastik, lihat misal Stander (2005) dan Rosadi, et.al (2008) untuk penjelasan lebih detail. Salah satu model parametrik yang dikenal adalah model Nelson Siegel, dengan bentuk kurva instantaneous forward-rate $f(t, m)$ diberikan dalam bentuk ${ }^{[3]}$.

$$
f(t, m)=\beta_{0}+\beta_{1} \exp \left(-\frac{m}{\tau}\right)+\beta_{2} \frac{m}{\tau} \exp \left(-\frac{m}{\tau}\right)
$$

Dengan demikian diperoleh kurva imbal hasil berbentuk :

$$
R(t, m)=\frac{1}{m} \int_{x=0}^{m} f(x) d x=\beta_{0}+\beta_{1}\left[\left[1-\exp \left(-\frac{m}{\tau}\right)\right] / \frac{m}{\tau}\right]+\beta_{2}\left[\left[\left[1-\exp \left(-\frac{m}{\tau}\right)\right] / \frac{m}{\tau}\right]-\exp \left(-\frac{m}{\tau}\right)\right]
$$

Bentuk peluruhan eksponensial dijelaskan oleh parameter $\tau$ dan $\beta_{0}, \beta_{1}, \beta_{2}$ dapat diinterpretasikan sebagai komponen long-term, short term dan medium-term dengan $m$ menunjukkan waktu sampai jatuh tempo. Parameter $\beta_{0}$ dan $\tau$ bernilai positif dan $\beta_{0}+\beta_{1}>0$.

Untuk menambah fleksibilitas dan ketepatan kurva, Svensson (1994), menambah fungsi Nelson dan Siegel dengan "hump" kedua.

$$
\begin{aligned}
& R(t, m)=\beta_{0}+\beta_{1} \times\left[\frac{1-\exp \left(-m / \tau_{1}\right)}{m / \tau_{1}}\right]+\beta_{2} \times\left[\frac{1-\exp \left(-m / \tau_{1}\right)}{m / \tau_{1}}-\exp \left(-m / \tau_{1}\right)\right] \\
& +\beta_{3} \times\left[\frac{1-\exp \left(-m / \tau_{2}\right)}{m / \tau_{2}}-\exp \left(-m / \tau_{2}\right)\right]
\end{aligned}
$$

Pada kurva ini, nilai $\beta_{0}, \tau_{1}$ dan $\tau_{2}$ selalu bernilai positif. 


\section{Estimasi Model NSS dan Komputasinya dengan R}

Model Nelson-Siegel-Svensson dapat diestimasi menggunakan metode optimisasi model regresi non linear dengan pembatas (constrained nonlinear regression optimization) berdasarkan fungsi YTM diatas. Secara umum terdapat dua metode alternatif untuk estimasi model, yakni menggunakan algoritma metode non linear secara penuh (dinamakan full estimation algorithm), maupun menggunakan pendekan parsial, yakni pertama-tama nilai $\tau_{1}$ dan $\tau_{2}$ ditentukan terlebih dahulu dan kemudian dilakukan estimasi nilai-nilai $\beta$, atau sebaliknya, menentukan nilai-nilai $\beta$ terlebih dahulu, baru kemudian mengestimasi nilai-nilai $\tau^{[1]}$. Untuk pendekatan pertama, estimasi dapat dilakukan misal pendekatan Sequential Quadratic Programming (SQP), Nelder-Mead Simplex method, ataupun dengan pendekatan optimisasi dengan pembatas lainnya ${ }^{[2]}$.

Dalam paper ini, diberikan contoh implementasi optimisasi regresi non linear dengan pembatas dari fungsi YTM diatas menggunakan perintah nlminb yang mengimplementasikan pendekatan optimisasi PORT (http://netlib.belllabs.com/netlib/port/). Fungsi R yang mengimplementasikan pendekatan ini diberikan pada bagian akhir dari paper ini. Sebagai alternatif, dapat juga digunakan constrOptim yang mengimplementasikan pendekatan Nelder-Mead ataupun metode lain seperti metode "BFGS"/quasi-Newton dan metode conjugate gradients. Lebih lanjut, versi GUI dari estimasi fungsi YTM ini berdasarkan implementasi ini tersedia pada paket RcmdrPlugin.Econometrics ${ }^{[4]}$. Contoh aplikasi dari paket ini diberikan pada Gambar 1 sampai Gambar 4.

\section{Kajian Empirik}

Untuk mengilustrasikan pendekatan yang diberikan diatas, pada bagian ini diberikan contoh implementasi dari model menggunakan data obligasi tanpa kupon yang ditawarkan oleh pemerintah Indonesia dan ditransaksikan pada tanggal 5 Mei 2010. Data yang tersedia terdiri atas 97 data transaksi harian, sebagaian kecil diberikan pada Tabel 1 berikut.

Tabel 1. Data Transaksi Obligasi Pemerintah tanggal 5 Mei 2010

\begin{tabular}{|c|c|c|c|c|c|c|}
\hline No & Trade_date & Prod_Code & Price_inpercent & Yieldv & Maturity & TTM_inYear \\
\hline 1 & 5-May-10 & FR0022 & 105.75 & 7.4201 & 15-Sep-11 & 1.3644 \\
\hline 2 & 5 -May-10 & FR0022 & 106.25 & 7.0317 & 15 -Sep-11 & 1.3644 \\
\hline 3 & 5 -May-10 & FR0022 & 106.25 & 7.0317 & $15-$ Sep-11 & 1.3644 \\
\hline & $\ldots \ldots$ & $\ldots .$. & $\ldots$. & $\ldots$. & $\ldots$. & $\ldots$. \\
\hline 97 & 5-May-10 & FR0052 & 103.75 & 10.0592 & 15-Aug-30 & 20.2932 \\
\hline
\end{tabular}

Menggunakan fungsi R pada Lampiran 1, diperoleh output berikut:

> IGSYCModel.1 <- NSSest(rate=as.data.frame(obligasi[,"Yieldv"]),

+ inputvars=as.data.frame (obligasi[, "TTM_inYear"]),model="NSS",methodest="direct",

+ doplot=1)

> IGSYCModel.1\$par

beta0 betal beta2 beta3 lambdal lambda2

$\begin{array}{llllll}11.1409177 & 1396.2599406 & -398.5462887 & -2685.5514846 & 1.0451446 & 0.3961868\end{array}$ 
Grafik kurva imbal hasil untuk data ini diberikan pada Gambar 1. Menggunakan versi GUI dari perintah ini pada plugin RcmdrPlugin.Econometrics, akan diperoleh output grafik dan parameter model yang sama. Perhatikan Gambar 2- Gambar 4 pada lampiran.

\section{DAFTAR PUSTAKA}

1. Bolder, D. and Stréliski, D., Yield Curve Modelling at the Bank of Canada, preprint, 1999.

2. Lange, K., Numerical Analysis for Statisticians, Second Edition, Springer Verlag, New York, 2010.

3. Nelson, C. R. and Siegel, A. F., Parsimonious Modeling Of Yield Curves, Journal of Business, 1987, 60, No. 4, 473-89.

4. Rosadi, D., Analisa Ekonometrika dan Runtun Waktu dengan $R$ : Aplikasi untuk bidang Ekonomi, Bisnis dan Keuangan, Andi Offset, Yogyakarta, 2011.

5. Rosadi, D., Gunardi, Abdurakhman, Utami, H. and Wulansari, Y., Validation and Goodness of Fit Test for Indonesian Government Securities Yield Curve, Research Report, Department of Statistics - Gadjah Mada University and Indonesian Bond Pricing Agency, 2008.

6. Svensson, L. E. O., Estimating And Interpreting Forward Interest Rates: Sweden 199294, IMF Working Paper No. 114, 1994.

7. Stander, S.Y., Yield Curve Modeling, Palgrave Macmilan, New York, 2005. 


\section{Lampiran 1. Kode Program R untuk Estimasi Fungsi NSS}

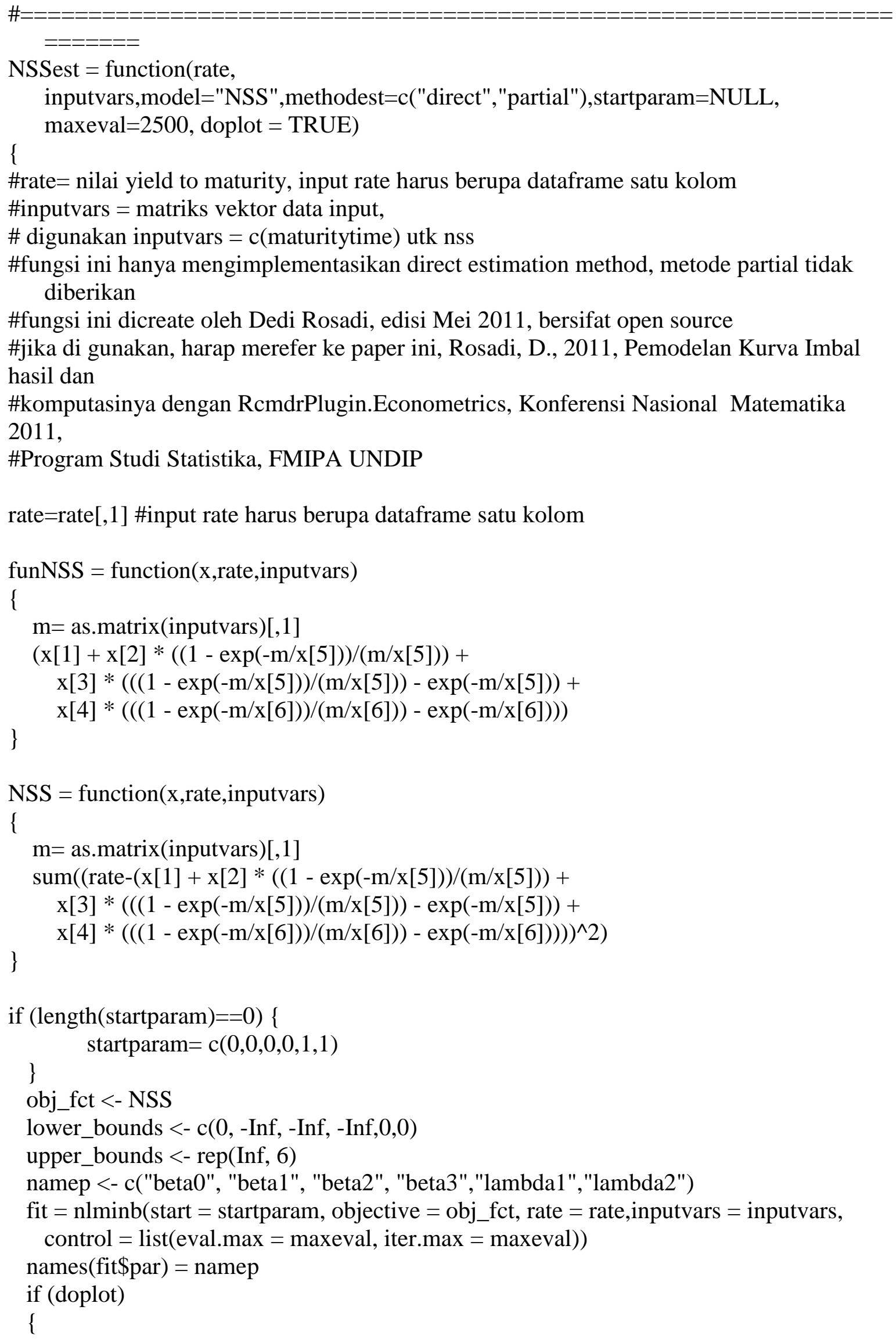




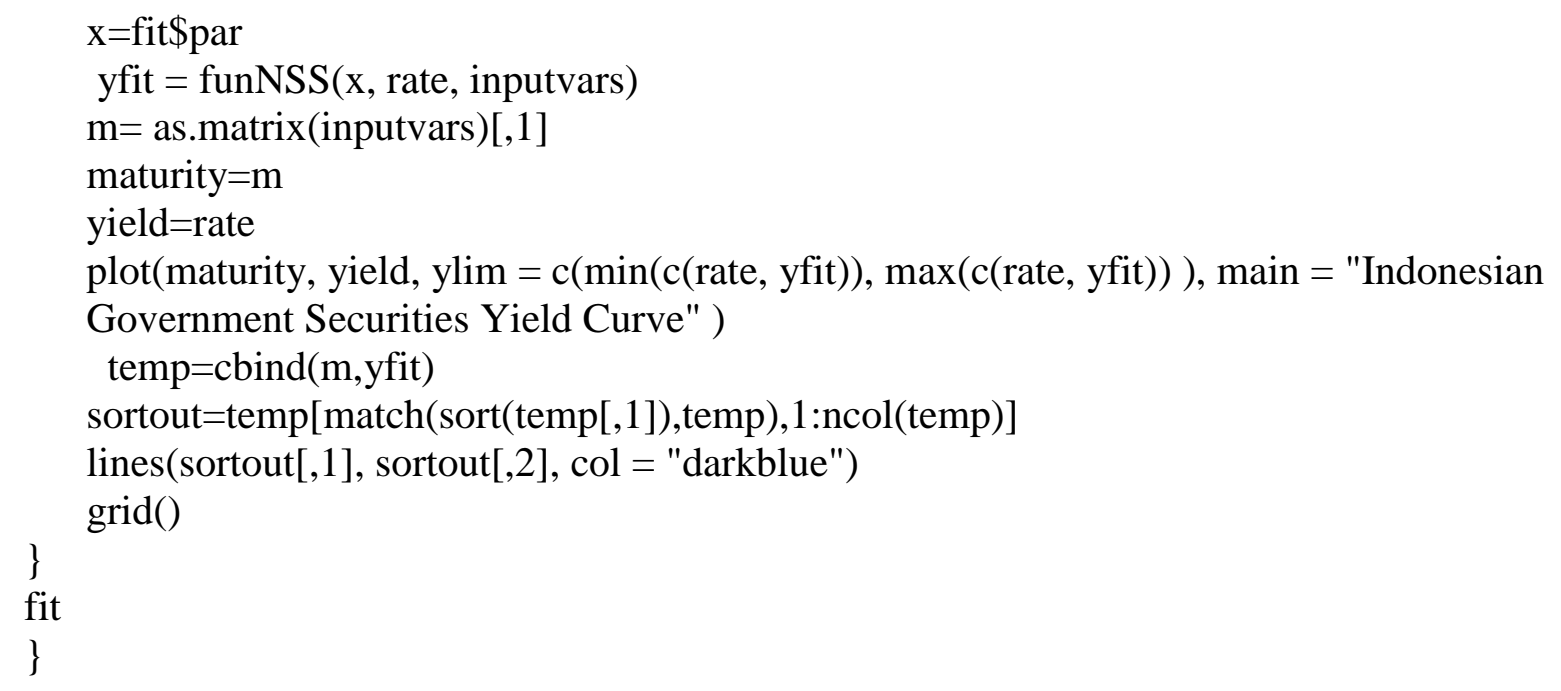




\section{Lampiran 2.}

\section{Indonesian Government Securities Yield Curve}

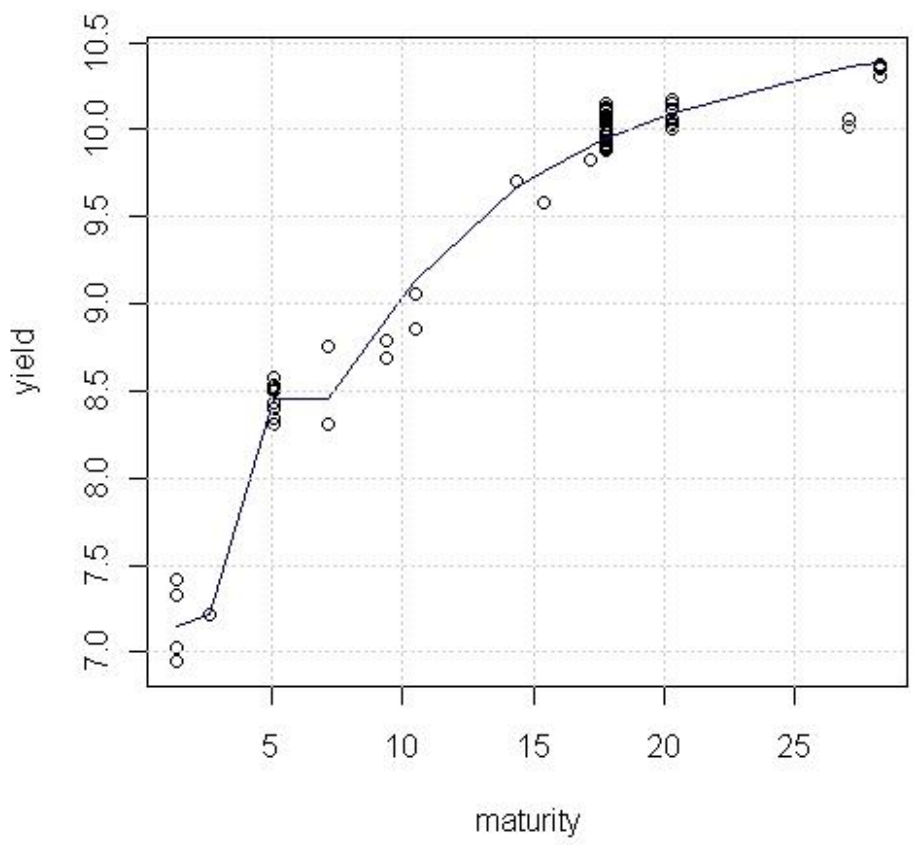

Gambar 1. Grafik Hasil Estimasi Kurva Imbal Hasil 


\section{Lampiran 3. Estimasi Kurva Yield dengan Program GUI RcmdrPlugin.Econometrics}

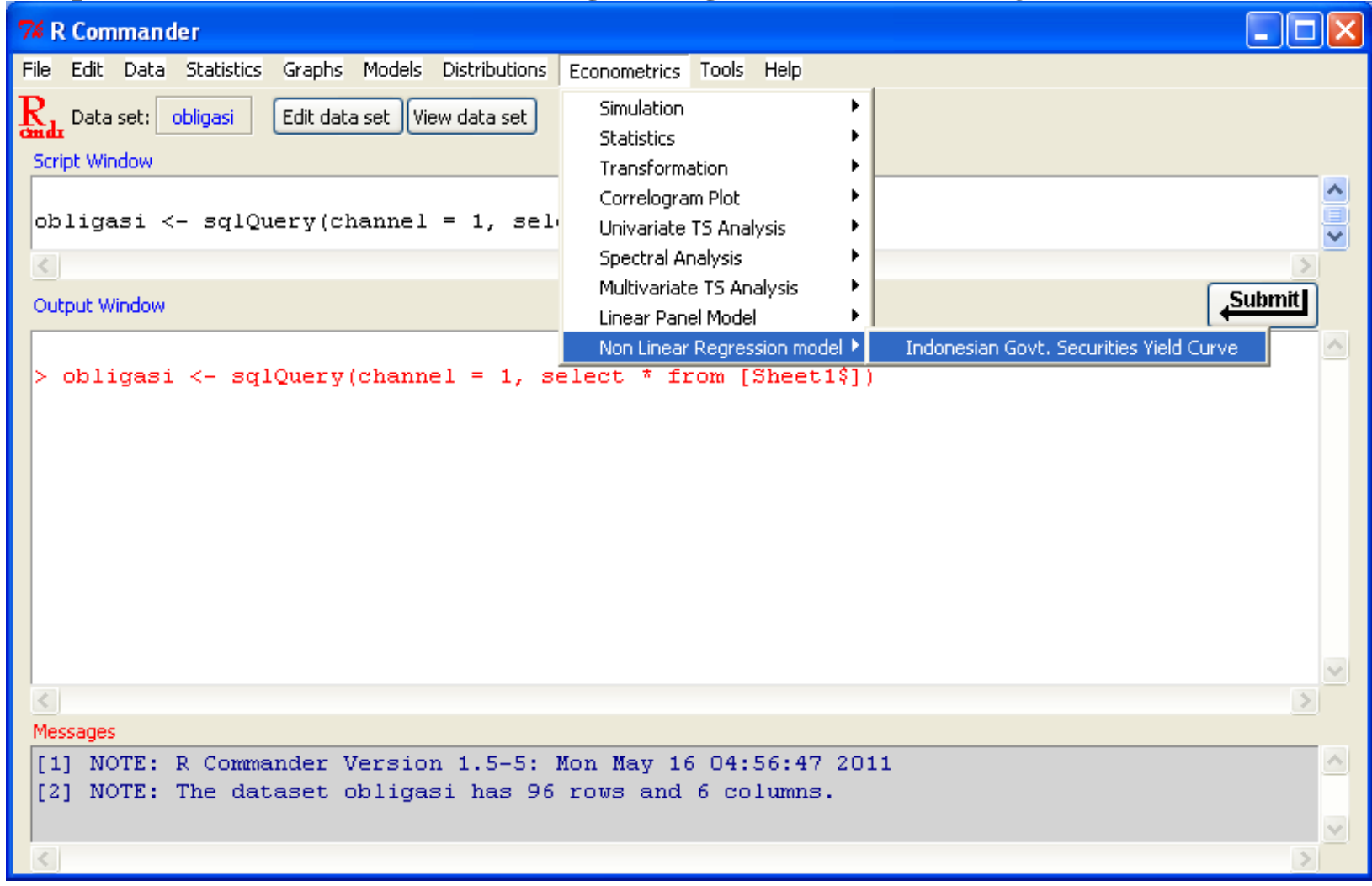

Gambar 2. Dialog Estimasi Kurva Yield dengan NSS pada RcmdrPlugin.Econometrics

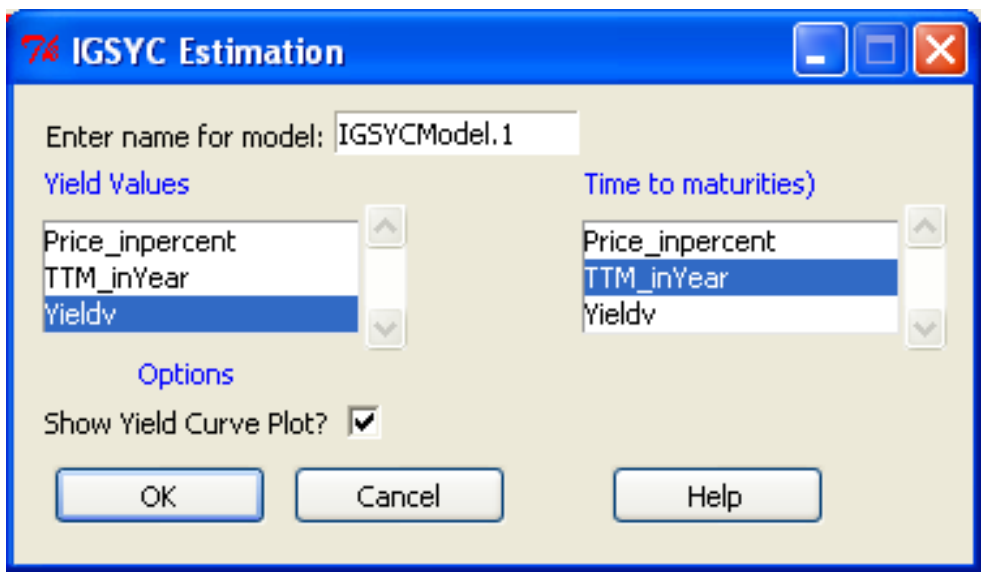

Gambar 3. Jendela Dialog Estimasi Kurva Imbal Hasil 


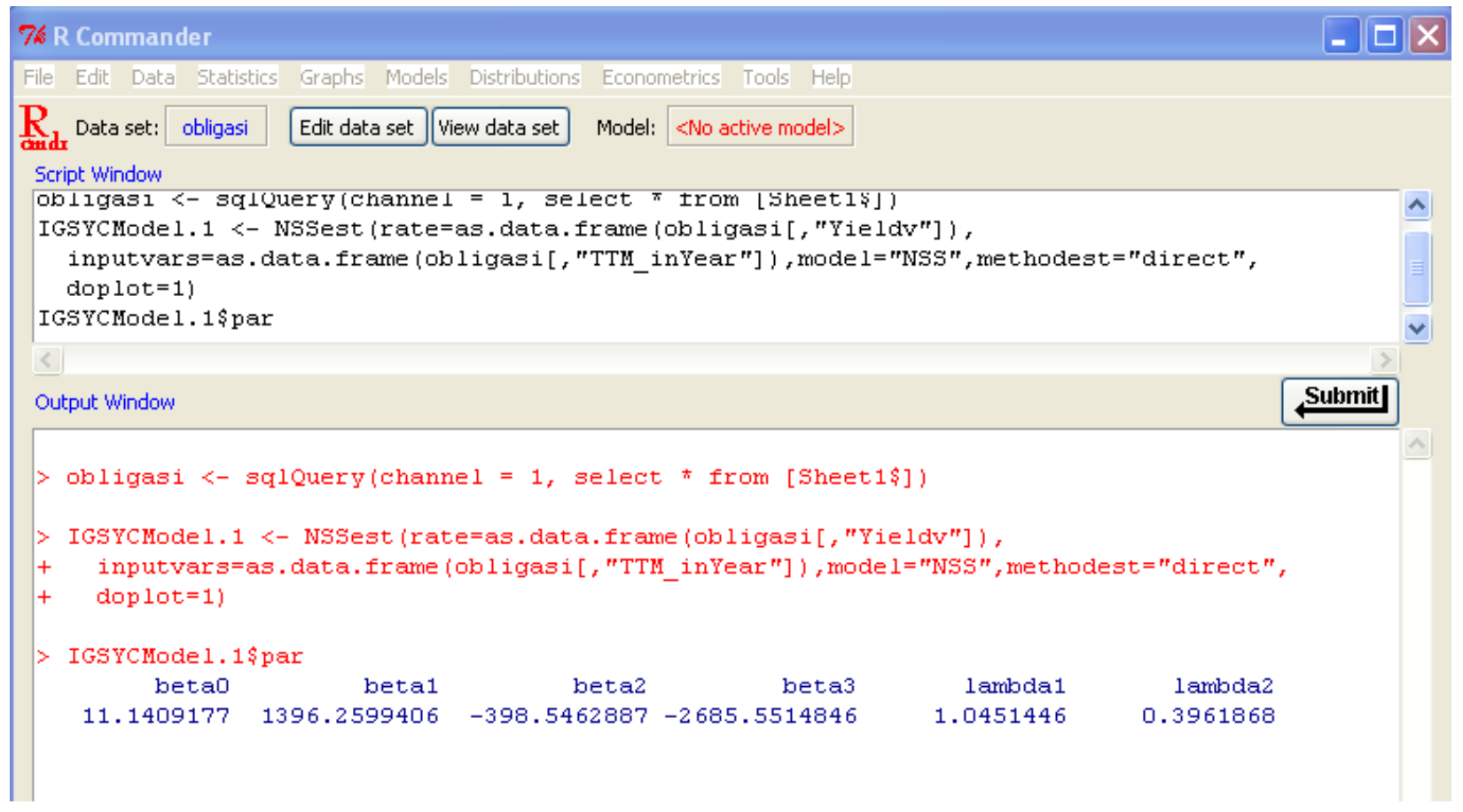

Gambar 4. Jendela Output pada RcmdrPlugin.Econometrics untuk Estimasi Model NSS 